Ärztliche Erfahrung beschränkt sich nicht auf medizinisches Fachwissen.

\title{
Mit diesem einfachen Trick sind alle Einschlafprobleme passé
}

Auch Frust gehört

zum Leben.

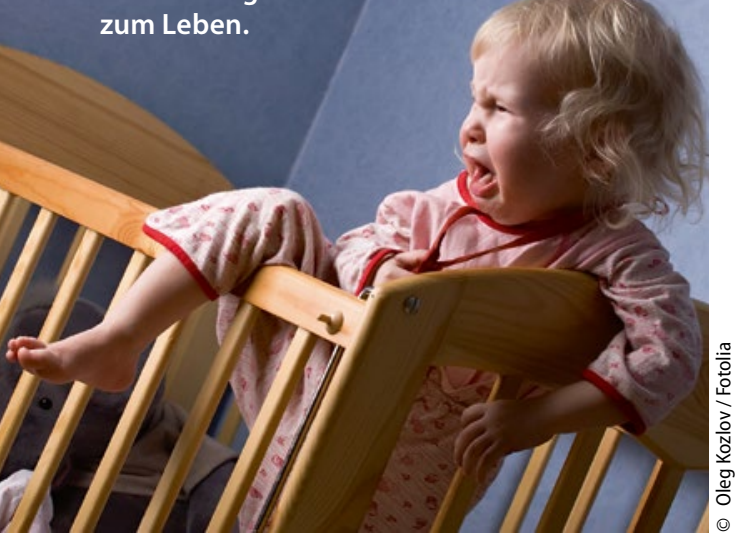

Eine Mutter kam mit ihrer anderthalbjährigen Tochter zu mir, einem zarten, aufgeweckten Mädchen. Die Kleine war altersgerecht schüchtern, aber offensichtlich sehr interessiert am Mobiliar des Behandlungszimmers.

Während ich dies registrierte, schilderte mir die Mutter ihre Sorgen. Das Einschlafen war ein Riesenproblem, es dauerte 2-3 Stunden. Immerzu stand die Kleine auf, um zu spielen oder die Schränke auszuräumen. Ich erfuhr, dass sie im Bett der Eltern schlafen gelegt wurde und die Mutter sich händchenhaltend dazulegte. Beim Hinübertragen ins eigene Gitterbett fing die Kleine dann stets an zu schreien. Nun wünschte die Mutter eine homöopathische Behandlung dieser „Einschlafstörung“.

Ich wagte es, ihr zunächst einmal einen Rat zu geben: Ihre Tochter sei in einem Alter, in dem es für ihre Entwicklung notwendig sei, ihre Mutter als eigenständige Person wahrzunehmen. Dazu gehöre auch das Erkennen, dass ihre Wünsche nicht immer denen ihrer Eltern entsprechen. Sie würde verstehen, wenn die Mutter ihr sage, dass sie liegenbleiben müsse, wenn sie im Elternbett schlafen wolle. Sonst müsse es heißen: „Ab ins eigene Bett!“

\section{Das Kind ist sehr wohl folgsam}

Meine Einschätzung kam nicht von ungefähr: Kurz zuvor hatte das Mädchen auf mein Verbot, den Sprechzimmerschrank zu öffnen, reagiert und sich anderweitig beschäftigt. Somit hatte es den Beweis selbst erbracht. Ich fügte hinzu, dass das Erleben und Aushalten von Frustrationen sehr wichtig sei.

Dies schien bei der Mutter Eindruck zu machen, die doch ihre Tochter immer zufriedenstellen wollte. Nun näherten wir uns dem Kern des Problems: Die besorgte Mutter war sich nicht sicher, ob sie selbst es ertragen könnte, ihr Kind schreien zu hören. Ich beglückwünschte sie zu dieser Einsicht und meinte, dass sie dafür eine Lösung finden würde.

Eine Woche später telefonierten wir. Eine Behandlung war nicht mehr erforderlich. Sie hatte ihre Tochter ins Kinderbett schlafen gelegt, wo die Kleine nur drei (lange) Minuten geschrien hatte. Dann war sie eingeschlafen - und seitdem gab es keine Probleme mehr.

Dr. Andrea Linsel, Lüneburg

\section{Spaß am Leben: Dem Krebs mit Sildenafil trotzen}

Dieser Mann war wirklich vom Schicksal gebeutelt: Mit über 60 Jahren hatte er bei einem schrecklichen Verkehrsunfall ein Polytrauma erlitten. Stunden war er in unwegsamem Gelände in seinem Wagen eingeklemmt, bis er gerettet wurde. Tapfer hatte er sich wieder zurück ins Leben gekämpft, als ihn nach einem Jahr der nächste Schicksalsschlag ereilte. Bis dahin hatte man seine Magenschmerzen auf eine stressbedingte Gastritis zurückgeführt, aber bei einer Gastroskopie hatte man ein großes Adenokarzinom gefunden. Tapfer hatte er sich der OP gestellt. Nun erholte er sich von dem Eingriff.

Vor der geplanten Chemotherapie besuchte mich seine Frau, um ein paar Dinge zu besprechen. Die Schicksalsschläge hatten weder ihre Attraktivität noch ihren Schwung gemindert. „Darf man unter Chemotherapie eigentlich Viagra nehmen?", fragte sie mich unverhofft. Ich stutzte kurz und bat sie dann, das mit dem Onkologen zu besprechen, auch wenn meiner Auffassung nach dagegen nichts einzuwenden wäre. „Aber haben Sie beide denn Lust?", fragte ich leicht zweifelnd. Sie lächelte strahlend: „Wir haben immer viel Freude daran gehabt. Warum sollen wir uns von so einem Quatsch den Spaß nehmen lassen?!“. Ich lächelte zurück. Stimmt. Warum eigentlich sollten sie?

Dr. Frauke Höllering, Arnsberg 